\title{
Análise cronológica da indústria petrolífera
}

\author{
Chronological analysis OF THE OIL INDUSTRY
}

\author{
Victor do Amaral Cruz Freret, Hernani Aquin Fernandes Chaves, Cleveland Maximino Jones \\ Univ. do Estado do Rio de Janeiro. Faculdade de Geologia. RJ, Brasil. \\ E-mall: GeologiA.Freret@gmall.com. ; Hernani@uer..br/HafChaves@gmall.com; clevelandmJones@gmall.com
}

Abstract: In this study, a bibliographical survey regarding the history of the petroleum industry was carried out in order to build a better understanding of the oil industry from its beginning, formation and subsequent development. In addition, an understanding of the possible factors influencing it, for example, oil prices, available reserves and geopolitics, was sought.

\author{
Manuscript: \\ Recebido: 07/02/2018 \\ Correção: 21/09/2018 \\ Aceito: 24/10/2018
}

Citação: Freret, V. A. C., Chaves, H. A. F., \& Jones, C. M. 2019. Análise cronológica da indústria petrolífera. Terræ Didatica, 15, 25-32, e019004. doi:10.20396/td.v15i0.8654690

Palavras-chave: História do petróleo, indústria petrolífera, petróleo, preços do petróleo.

\section{Introdução}

Os primeiros indícios da existência de petróleo são datados desde as antigas civilizações, entretanto, com a perfuração do primeiro poço de petróleo no mundo em 1859, nos Estados Unidos, há uma mudança no comportamento das relações geopolíticas e econômicas. Enquanto o petróleo se consolidava como principal fonte de energia na matriz energética mundial iniciou-se a intensa procura pelo produto, por meio de sua exploração e do desenvolvimento de tecnologias para a sua produção, o que tornava o negócio muito rentável, além de fortificar o mercado desse produto (Shah, 2007).

Com as transformações políticas e econômicas geradas por conta da exploração, comercialização e demanda do petróleo, ocorreram crises nesse setor, fazendo com que países considerados grandes produtores e exportadores de petróleo adotassem estratégias para que mantivessem o controle da indústria petrolífera mundial, consolidando assim, novos agentes no cenário político-econômico mundial. Sob essa perspectiva e considerando a importância do petróleo para a base energética mundial, o presente trabalho teve como intuito fornecer uma perspectiva histórica do início e evolução da indústria do petróleo.

\section{Materiais e Métodos}

Para a elaboração do presente artigo, foi realizado um levantamento bibliográfico a partir dos temas relacionados com a pesquisa, a fim de trazer uma abordagem histórica acerca da indústria do petróleo. O levantamento de dados foi feito por meio da consulta de publicações científicas pertencentes à base de dados do Portal de Periódicos da Capes, Google Acadêmico e outros mecanismos de busca de artigos científicos. Para a localização dos artigos nas respectivas bases de dados, adotaram-se palavras-chave nos idiomas português e inglês, sendo elas: "petroleum history", "petroleum industry", "evolução indústria petrolifera". Para que houvesse um melhor refinamento da pesquisa a ser feita, utilizou-se o conectivo booleano "AND" para recuperar os assuntos relacionados entre si, como por exemplo: "petroleum and history" e "evolução and petróleo". A partir dos arquivos gerados nos mecanismos de busca, foi criada uma base de dados utilizando-se o software Mendeley Desktop. Desse modo, o procedimento adotado foi a criação de uma pasta dentro do software para a base de dados e, posteriormente, adicionaram-se os trabalhos científicos encontrados predominantemente nos formatos de artigos de periódicos. 


\section{Histórico da Indústria do Petróleo}

A presença do petróleo na vida do homem é possível de ser notada desde os tempos bíblicos, quando vários povos o utilizavam de inúmeras formas, desde o assentamento de tijolos com asfalto até o embalsamamento dos mortos. Já durante a Idade Média, seu uso ficou restrito somente a fins farmacêuticos (Yergin, 1990). Ainda que possa se remontar a utilização do petróleo à Antiguidade, seu uso em uma escala mais ampla, devido à aplicação como iluminante, ocorreu em meados de 1850 no ocidente europeu, tendo sua extração sido feita por meio de poços cavados manualmente pelos camponeses e posteriormente refinado em querosene (Yergin, 1990).

Assim, por mais que a descoberta do petróleo não seja síncrona ao início de sua indústria, faz-se necessário demonstrar o conhecimento prévio dessa substância pelas civilizações antigas, a fim de que seja considerado neste artigo o conceito de indústria petrolífera moderna.

\subsection{Pioneiros e transformadores da indústria}

Segundo Tugendhat \& Hamilton (1975), um dos acontecimentos significativos da indústria petrolífera moderna foi George Bissel ter observado uma rudimentar indústria de coleta de óleo, realizada por meio de escumadeiras e trapos, durante seu percurso pelo oeste da Pensilvânia em 1853. Mediante o entendimento de que aquele produto poderia ter potencial energético e econômico significativo, ocorre a criação da Pennsylvania Rock Company, considerada a primeira empresa de petróleo do mundo. Posteriormente, Bissel contrata um renomado químico e professor do século XIX, chamado Benjamin Sillimans, a fim de legitimar as características desse óleo como iluminante e lubrificante.

Com o objetivo de explorar as bacias sedimentares presentes na parte noroeste das Pensilvânia, na região de Titusville, Sillimans e Bissel fundam uma nova empresa intitulada Seneca Oil Company. A operação das atividades foi incumbida a Edwin Drake, chamado de Coronel Drake, que em 27 de agosto de 1859, nas planícies do Oil Creek Valley furou o primeiro poço de petróleo, tendo uma produção de 20 barris/dia a uma profundidade aproximada de 20 metros. Considera-se a data como sendo o marco inicial da indústria petrolífera moderna (Aragão, 2005).
As terras do Oil Creek Valley foram palco da grande corrida pelo ouro negro, sendo procurada por muitos aventureiros e por inúmeras empresas petrolíferas, entusiasmados com a descoberta de Drake. Essas empresas pleiteavam as regiões exploráveis, tendo por finalidade a produção no menor tempo e na maior proporção possível, ocasionando danos nos reservatórios ou até exaurindo precocemente os poços (Freret, 2017). A concorrência caótica e a produção desenfreada levaram a uma elevação exorbitante no volume produzido gerando uma enorme flutuação do preço do barril do petróleo. Com isso, ocorre a troca do óleo de baleia e outros tipos de iluminantes pelo petróleo (Souza, 2006).

De acordo com Yergin (1990), no princípio, a indústria e o mercado de petróleo se fundamentavam na produção de somente um tipo de derivado, que era o querosene utilizado na iluminação, sendo considerado uma alternativa para o óleo de baleia, visto que, a caça deste animal estava em direção à extinção. Depois do refino, eram descartados todos os demais derivados do petróleo. O nível tecnológico da indústria petrolífera se equiparava ao desenvolvimento da tecnologia no mundo naquele período: as regiões exploradas eram em terra, de mais fácil perfuração, via percussão e com o uso de ferramentas rudimentares. O reconhecimento do petróleo se dava pela localização visual de indicativos de sua presença, isto é, as jazidas de petróleo só seriam exploradas caso houvesse exsudação de óleo, ou seja, uma pequena quantidade de óleo aflorada naturalmente à superfície do solo (oil seeps).

Com o final desta fase, notaram-se avanços tecnológicos nessa indústria como: 1) O escoamento da produção até seus mercados de consumo, com a troca de barris de madeira transportados por meio de cavalos e carroças, por oleodutos (também feitos de madeira) que ligavam as Oil Regions às ferrovias; 2) Um melhor domínio da pressão do gás através do uso de novos procedimentos de perfuração, reduzindo assim os prejuízos; 3) O aumento na relevância do refino, setor de extrema importância para um posterior crescimento da indústria, pelo fato do surgimento da iluminação elétrica com a criação da lâmpada incandescente por Thomas Edison no ano de 1877, frente ao uso do querosene iluminante.

A história da indústria do petróleo foi marcada pelo americano John D. Rockefeller, considerado um pioneiro por ter conseguido integrar as atividades desse setor, como a capacidade de arma- 
zenamento, transporte, refino e venda de seus derivados. Conforme Aragão (2005), por meio de novas técnicas gerou-se um aperfeiçoamento da produtividade e qualidade dos derivados, ocasionando uma diminuição de seu custo pós-refino, além do aumento da lucratividade. Tendo a qualidade de seus produtos ofertados ao mercado como carro chefe, Rockefeller inspirou-se inclusive para o nome de sua empresa: Standard Oil Company. Entretanto, a razão deste americano ter marcado a história da indústria do petróleo se dá pelo fato de ter buscado e alcançado a sua integração, o que foi considerado uma revolução econômica, dando início ao maior monopólio da economia americana do século XIX.

Para que se tenha uma noção do monopólio exercido pela Standard Oil, de 1880 a 1890, dominava $90 \%$ do transporte por meio de oleodutos e ferrovias, cerca de $80 \%$ da capacidade de refino e $90 \%$ da distribuição e comercialização de produtos, que se difundiram na Europa, Ásia, África do Sul e Austrália. Mediante isso, em 1900, o truste controlado por Rockefeller operacionalizava cerca de $70 \%$ de suas atividades fora dos Estados Unidos (Yergin, 1990).

Por terem ocorrido de forma rápida, esses acontecimentos geraram certo receio na sociedade americana. O governo, pressionado pela mobilização política da sociedade, criou o Sherman Act, dando início a um conjunto de reformas progressistas da Segunda Revolução Industrial americana e a regulamentação e gerência dos grandes negócios (Yergin, 1990).

Em 1911, a Suprema Corte Federal dos Estados Unidos determinou a divisão do monopólio em 33 empresas, das quais algumas se tornaram as maiores da IMP (Indústria Mundial do Petróleo). Empresas como a Standard Oil of New Jersey, que viria a se tornar a Esso e Exxon; a Standard Oil of New York, posteriomente Mobil Oil e a Standard Oil of California, após Socal, hoje Chevron, são exemplo. Estabelece-se assim o início de uma nova etapa da indústria do petróleo, que tem como base a concorrência entre grandes companhias.

\subsection{Internacionalização e desenvolvimento da indústria petrolífera}

Ao mesmo tempo em que a indústria de petróleo nos Estados Unidos evoluía, iniciava-se a perfuração dos primeiros poços no continente europeu. Com o início da abertura do mercado europeu para empresas não pertencentes ao império de Rockefeller, em 1890, fundou-se a empresa holandesa Royal Dutch Petroleum, tendo sua produção iniciado na região das Índias Holandesas. Já no ano de 1897, nasce a companhia inglesa Shell Transport and Trading Company, que em conjunto com a Royal Dutch Petroleum, detinham mais da metade das exportações de petróleo da Rússia e do Oriente Médio.

Pelo fato da produção de petróleo no continente europeu estar descontrolada nessa época, causando deterioração dos preços, as vendas da Standard Oil eram facilitadas, pois a mesma havia adotado a política de subsídios cruzados. Com isso, as lideranças das grandes empresas europeias criaram uma aliança entre si a fim de avançar sobre os espaços econômicos mundiais nos quais se exercia o controle da Standard Oil of New Jersey, surgindo, assim, a Royal Dutch Shell. Além disso, em função da descoberta de petróleo na Pérsia (atual Irã), cria-se a Anglo Persian Oil Company (atual BP), estabelecendo uma maior concorrência no setor petrolífero.

No início do século $X X$, uma nova perspectiva é aberta à indústria do petróleo, por meio da descoberta de novas províncias petrolíferas, do surgimento de novas empresas, da difusão da eletricidade e do aparecimento e rápida ascensão do automóvel. Atentas às transformações do mercado, as empresas adequaram as refinarias para produzir gasolina, a qual superou o consumo de querosene em 1910 (Freret, 2017).

A gasolina e o óleo combustível assumiram papel de destaque na indústria petrolífera com o início da Primeira Guerra Mundial em 1914, pois eram considerados essenciais para a mobilidade das tropas, ocasionando o crescimento do uso de derivados de petróleo. Com isso, há a necessidade de que novas áreas ou campos entrem em produção, iniciando-se assim, a competição oligopólica na indústria mundial do petróleo para conquistar as jazidas de petróleo do Oriente Médio e novas fontes de fornecimento na Ásia e América Latina, seja para exploração e/ou compra da produção.

\subsection{0 estabelecimento das concessões, consórcios e a formação de cartel internacional}

Para que o desenvolvimento da IMP continuasse a ocorrer, foi necessário que as grandes empresas mundiais compreendessem a importância de se controlar o crescimento dessa indústria. Com o objetivo de se conter a superprodução e as guerras de preço, que prejudicavam a rentabilidade da 
IMP, era estrategicamente imprescindível possuir o controle do suprimento de óleo cru. Para isso, dependia-se de dois fatores: em primeiro lugar, a definição dos direitos de propriedade e da gerência das reservas pelas grandes empresas em países do Oriente Médio. Em segundo lugar, a adesão das majors de um gerenciamento oligopolista, que alocasse níveis de produção e posterior suprimento de demanda em áreas geográficas da indústria, a fim de evitar práticas competitivas que pudessem ameaçar a IMP. Ambos fatores foram implementados, sendo o primeiro com o uso do sistema de concessões e o segundo por meio da formação de associações ou consórcios (Souza, 2006).

As concessões foram utilizadas com o propósito de regulamentar as relações entre os governos de países detentores de reservas de óleo cru e as grandes companhias internacionais. Essas regulamentações foram feitas, de tal modo que, ao se obter a concessão, era concedida à empresa um "direito absoluto" sobre uma determinada área sob a alçada de um Estado, na qual se permitia a procura, extração e comercialização de óleo com preços determinados pela concessionária, mediante compensação financeira.

Os consórcios foram projetados para ser o principal mecanismo regulatório das relações entre as companhias, particularmente na etapa estratégica e de extrema importância de crescimento da produção de cru, iniciada pós 1925. O primeiro consórcio, denominado Iraq Petroleum Company (IPC) fundado em 1928, juntou as maiores empresas de petróleo do mundo por meio do Acordo da Linha Vermelha. Este primeiro consórcio (IPC) foi de extrema importância para o desenvolvimento da IMP por três razões: marcou a entrada definitiva no Oriente Médio pelas companhias americanas, foi utilizado como modelo na criação de consórcios em outros segmentos da indústria e legitimou a propriedade e a gestão em conjunto. O segundo acordo, firmado em 1928, intitulado Acordo Achnacarry, concretizou a formalização do cartel, consolidando as posições das majors mediante um acordo de divisão de mercados.

No início da década de 1930, como resultado dos acordos da Linha Vermelha e de Achnacarry, formou-se o "Cartel das Sete das Irmãs" (composto por Standard Oil of New Jersey (Exxon), Standard Oil of Califórnia (Chevron), Gulf Oil Co., Texaco, Mobil (sucessora da Socony-Vacuum Oil Co.), Royal Dutch-Shell e Anglo Iranian Oil Co. (BP)), originando joint ventures com o inuito de explorar campos petrolí- feros estrangeiros. $\mathrm{O}$ cartel começou as atividades no downstream (refino, transporte e distribuição) e, posteriormente, no upstream (exploração e produção) (Aragão, 2005). Para que se tenha ideia do controle das majors, em 1950, excluindo-se os países considerados socialistas, detinham $65 \%$ das reservas no mundo, mais do que a metade da produção de óleo bruto, $70 \%$ da capacidade de refino, os oleodutos de maior relevância e por volta de dois terços da frota mundial de petroleiros (Penrose, 1983).

Com o fim da Segunda Guerra Mundial, a demanda por energia aumentou consideravelmente, sendo que entre 1950 e 1973, a produção de petróleo foi multiplicada por 5,4, de eletricidade por 6 e a de gás natural por 6,3. As mudanças na produção de energia, ocasionadas pelos países em reconstrução pós-guerra e em processo de industrialização, sustentaram-se na importação pesada de petróleo e posteriormente, de gás natural (Yergin, 1990). Devido ao aumento da demanda mundial, em 1950, os esforços das "Sete Irmãs" foram concentrados nas bacias petrolíferas do Oriente Médio, onde detinham $99 \%$ da produção de óleo bruto (Freret, 2017).

Apesar do domínio do mercado mundial de petróleo por essas empresas, considera-se que a Segunda Guerra Mundial foi um ponto de inflexão na indústria petrolífera, visto que começou a diminuir o controle exercido pelas "Sete Irmãs", o que se tornou evidente no final dos anos 50 (Souza, 2006).

\subsection{0 surgimento das estatais petrolíferas}

Após a Segunda Guerra, constatou-se que a indústria petrolífera possuía um fundamental papel geopolítico, apresentando potencial para ser a responsável pela evolução produtiva das nações em desenvolvimento. A partir daí, esses países estabeleceram uma política mais exigente ao negociar os contratos de concessão, gerando o aparecimento das empresas estatais de petróleo. Nesta época alguns acontecimentos foram essenciais para a organização da atual indústria de petróleo, tais como: a nacionalização do petróleo mexicano em 1938; a volta do petróleo russo ao mercado europeu (década de 1950); o começo da internacionalização das empresas independentes americanas, chamadas de minors (década de 1960); a renegociação dos contratos de concessão na Venezuela; a deposição do Xá Iraniano Reza Pahlevi. Além disso, destaca-se também o aparecimento de novos países produtores, como a Nigéria e Indonésia; a Revolução Islâmica no Irã, 
fazendo com que os contratos de concessão fossem renegociados; e a criação de grandes estatais de petróleo, como a PDVSA (Petróleos de Venezuela) e a Petrobras (Brasil) (Freret, 2017).

Segundo Yergin (1990), devido à decisão unilateral das majors de reduzir quase $7 \%$ do preço do petróleo bruto originário do Oriente Médio, têm-se em 1960, a criação da Organização dos Países Exportadores de Petróleo (OPEP). Os países fundadores da OPEP (Arábia Saudita, Venezuela, Kuwait, Iraque e Irã) controlavam cerca de $80 \%$ das exportações de petróleo bruto no mundo. Ao longo da década de 1960 e início de 1970, há a associação de vários países detentores de grandes reservas a essa nova organização.

Com o surgimento da OPEP, fica evidente o desejo de pleitear uma parte maior das receitas geradas e do controle da produção por parte dos países detentores dessas reservas. À medida que ocorria a nacionalização ou a tomada de participação no capital das companhias concessionárias por parte desses países, era possível notar uma mudança considerável no regime jurídico da produção de petróleo no mundo (Freret, 2017).

Ao longo da guerra árabe-israelense, em 1967, foi imposto um embargo pela Arábia Saudita aos Estados Unidos e Grã-Bretanha pelo fato de serem aliados de Israel. Com o cenário de disputa causado pela guerra, ocorre a determinação pela OPEP de um aumento gradual do preço do barril do petróleo, que nos anos seguintes passou de US $\$ 1,80$ a US $\$ 11,65$ no início de 1974. Devido a estes acontecimentos, as 18 nações industriais mundiais criam a Agência Internacional de Energia (AIE), tendo como objetivo criar medidas contra a elevação dos preços e embargos da OPEP (Taverne, 1999).

De acordo com Souza (2006), os pontos decisivos da mudança de estrutura da indústria do petróleo foram: a estatização das empresas de petróleo pertencentes à países da OPEP e a ocorrência do primeiro choque de preços do barril de petróleo em 1973.

\subsection{Os choques petrolíferos}

$\mathrm{Na}$ década de 1970, por motivos políticos e econômicos, ocorreu o primeiro choque petrolífero. Em outubro de 1973, teve início a guerra entre Israel, Egito e Síria, alterando a geopolítica energética e a evolução dos países ao redor do mundo, apontando que o petróleo poderia ser usado como arma política.
Reunidos em Genebra (Suíça), em 1973, os países exportadores do Oriente Médio elevaram tendenciosamente o preço do barril do tipo Arabian Light de US\$2,99 para US\$ 4,12 dólares. Após poucos dias do início da guerra (chamada de guerra do Yom Kippur), a OPEP embargou as exportações que tinham como destino os países considerados parceiros de Israel (EUA e Holanda). Em dezembro de 1973, ocorreu um novo aumento nos preços, para US\$11,65.

As consequências da crise petrolífera foram menos intensas para os EUA, devido à menor dependência da importação do produto e à valorização do dólar, gerada pelo investimento, no mercado norte-americano, do excedente de dólares em poder dos exportadores. A curto prazo, os efeitos negativos foram sentidos pelo Japão e Europa. No caso de países subdesenvolvidos, por exemplo o Brasil, as consequências foram muito graves, pelo fato de terem custeado a crise através do pagamento de juros internacionais elevados, visto que as taxas de juros da dívida externa eram flutuantes (Shah, 2007).

Em virtude do choque, houve redução no domínio da indústria do petróleo pelas "Sete Irmãs", que foram privadas ao acesso às melhores jazidas do mundo e expulsas das áreas pertencentes à OPEP, marcando a transferência do poder de mercado para a OPEP, embora o controle do refino e da venda de derivados ainda tenha permanecido com as Sete Irmãs (Gomes, 2013).

O primeiro choque do petróleo marcou o fim do petróleo barato e abundante, fazendo com que os países industrializados, por não terem outra alternativa energética tão vantajosa, dependessem das importações de petróleo vendidas a preços elevados pela OPEP (Gomes, 2013).

O segundo choque do petróleo ocorreu em 1979 devido ao preço médio do barril de petróleo bater recordes com a deposição do Xá do Irã pela Revolução Iraniana. Com isso, ocorreu o fim do Consórcio Iraniano de Petróleo, tendo retirado momentaneamente do mercado mundial cerca de 6 milhões de barris/dia (Freret, 2017).

Os choques do petróleo provacaram as maiores mudanças observadas na estrutura de consumo energético mundial e no padrão estratégico na história da indústria petrolífera. A partir disso, iniciou-se a competição das majors pelas reservas de petróleo no planeta, a descentralização da produção, o melhor aproveitamento da energia usada para o aquecimento das moradias no hemisfério norte e 
a constante busca na substituição dos derivados de petróleo por outras fontes de energia, sobretudo eletricidade, gás natural e fontes renováveis (Souza, 2006).

\subsection{0 período pós-choque}

No período pós-choque, a partir da década de 1980, a OPEP passou a perder força como formadora de preços devido ao aumento da produção não-OPEP em um mercado de demanda estática, à medida que a demanda de petróleo da OPEP continuava declinante (Freret, 2017). Com esse cenário, o sistema demandava que a atuação de mercado da OPEP diminuísse, criando-se assim um cenário no qual 12 membros (do total de 13) produziriam ao máximo de suas cotas e a Arábia Saudita seria responsável por ajustar a produção da organização em relação à demanda global, reduzindo sua presença no mercado mais do que da OPEP

A conservação dos preços em níveis altos ocasionava dois efeitos: estimulava a entrada de novas companhias que tinham custos de produção mais elevados, permitindo que as mesmas (como tomadoras de preços) comercializassem todo o petróleo que conseguissem produzir. Com isso, em 1986, ocorre o Contra-Choque, quando a Arábia Saudita adotou a precificação orientada pelo mercado, em substituição a venda de petróleo a preços fixos, segundo o sistema de cotas de 1983. Como resultado, o preço do barril de petróleo caiu rapidamente de US $\$ 27$ para US $\$ 10$ em apenas três meses, sendo o Arabian Light negociado por menos de US\$ $8 / \mathrm{bbl}^{1}$. Em consequência, os países da OPEP e os EUA aumentaram a pressão para que o país retornasse ao sistema de cotas, fazendo com que produtores de alto custo fossem forçados a parar a produção de seus campos. Desse modo, a Arábia Saudita foi forçada a readotar o sistema de cotas, no entanto, estabeleceu que seu petróleo seria vendido ao preço oficial de US\$18/barril (bbl) (Souza, 2006).

A década de 1980 foi marcada por um período de aquisições das companhias internacionais e também pela redistribuição geográfica dos investimentos em novas regiões produtoras de petróleo. Posteriormente à nacionalização ocorrida nos países do Oriente Médio, as majors precisaram se reestruturar, a fim de assegurar o abastecimento de suas refinarias e de seus mercados consumidores. Consequen-

1 Barril, equivalente a 0,159m3 temente, a indústria petrolífera passou por um momento de megafusões, aquisições e parcerias. Dessa forma, as grandes companhias mantiveram seu destaque por meio do volume comercializado e da sua capacidade de refino (Martin, 1992).

Ao longo da década de 90, têm-se uma trajetória de estabilidade no preço do petróleo, mantendo-se, com algumas exceções, por volta de US\$ 15 - 20/bbl, excetuando-se apenas o período referente ao conflito no Golfo Pérsico, em 1990, em que o preço do petróleo (Arabian Light) era de US\$ 40/ bbl (BP, 2006).

O preço do petróleo oscilou no intervalo de US\$ 16 a US $\$ 24$ por barril entre o fim da Guerra do Golfo até 1997, excetuando-se um breve período de preços em torno de US\$ 14 no início de 1994 (BCB, 2000). Nos anos seguintes, os preços voltaram a crescer motivados pela força da economia americana e também pelo desenvolvimento das economias asiáticas. Para se ter uma ideia desse crescimento, de 1990 a 1997, o consumo mundial de petróleo teve um aumento de 6,2 milhões de bpd, sendo 300 mil bpd somente dos países asiáticos. Esse incremento no consumo mundial de petróleo atrelado à queda da produção russa contribuiu para a recuperação de preços até 1997 (WTRG, 2011).

Em 2001, com o enfraquecimento da economia norte-americana e o aumento da produção dos países não pertencentes à OPEP, ocorre uma série de reduções nas cotas dos membros da organização, chegando a um corte de 3,5 milhões de bpd em 1 de setembro (WTRG, 2011). No dia 11 de setembro ocorrem os atentados terroristas que ocasionaram uma queda nos preços do barril do petróleo, o que causaria novos cortes na produção pela OPEP. No entanto, mediante o clima político, a OPEP atrasou o incremento de cortes até janeiro de 2002, tendo diminuído sua cota em 1,5 milhão de bpd, juntando-se a vários produtores não-OPEP incluindo a Rússia. Isso teve o efeito desejado com os preços do petróleo indo para a faixa de US $\$ 25 /$ bbl em março de 2002.

Em 2002-2003, com a tentativa de golpe de estado pelo então presidente Hugo Chávez, o cenário político da Venezuela era de total instabilidade, ocasionando uma greve geral na PDVSA com o objetivo de exigir a antecipação das eleições gerais. Logo em seguida, em abril de 2003, os Estados Unidos invadem o Iraque com a justificativa de que o Iraque estava desenvolvendo armas de destruição em massa, pondo em risco a segurança mundial. 
Como consequência direta da invasão americana ao Iraque, ocorre à interrupção de parte da produção iraquiana. Em 2003, o preço do petróleo bruto foi negociado entre US\$20-30/bbl (WTRG, 2011).

De 2004 a 2008, os preços do barril de petróleo tiveram um aumento, chegando até US \$145,29/ bbl em julho de 2008. Esse aumento foi influenciado por inúmeros fatores, como o crescimento da economia global em 2004 e 2005, o aumento do consumo de gasolina e das tensões geopolíticas causadas pelo lançamento de mísseis pela Coréia do Norte em 2006 (Freret, 2017).

Com expectativas maiores de estoques de petróleo nos EUA em 2007 e a ocorrência da maior recessão dos EUA desde a Grande Depressão, com acentuada redução na demanda de petróleo, houve uma queda abrupta nos preços, chegando a menos de US\$ 40/bbl em dezembro. Em 2009 e 2010, os preços do barril do petróleo oscilaram bastante, chegando a US $\$ 90 / \mathrm{bbl}$, causados pela baixa cotação do dólar e pelo programa do Banco Central Americano chamado de Federal Reserve System (FED) (EIA, 2010).

No ano de 2011, ocorreu a Primavera Árabe no norte da África e no Oriente Médio, que foram revoltas políticas contra governos centralizadores, ocasionando a queda das ditaduras na Líbia, Egito, Iêmen e Tunísia e iniciando o desenvolvimento de uma guerra civil na Síria que se mantém até hoje (Janeiro de 2018). Devido a estas revoltas em áreas produtoras de petróleo, a oferta da commodity foi afetada, e o preço do barril do petróleo aumentou, chegando a US $\$ 100 / \mathrm{bbl}$ (EIA, 2016).

Entre 2012 e 2014, o preço do barril se manteve estável na faixa entre US $\$ 80$ a US $\$ 100 / b b l$, entretanto, em janeiro de 2015 chegou a ser negociado com valores abaixo de US $\$ 50$, atingindo US $\$ 27$ em janeiro de 2016. Essa queda se originou com o excesso na oferta de petróleo no mercado mundial, tendo sido impulsionada pelo aumento na produção mundial. O crescimento da produção mundial se deu devido aos investimentos na extração de óleo e gás de folhelhos (shale oil e shale gas) pelos EUA e Canadá (Bloomberg, 2014).

No entanto, desde novembro de 2014, a OPEP se recusou a diminuir sua produção independentemente do preço do petróleo no mercado internacional. Essa decisão tomada pela OPEP, especialmente pela Arábia Saudita, que é o maior produtor da organização (EIA, 2017) e o segundo no mundo em reservas (EIA, 2015), teve como objetivo a tentativa de inviabilizar a produção de shale oil e shale gas norte-americana e a de países concorrentes, como o Irã. Apesar de sua economia ser muito dependente do setor petrolífero, a Arábia Saudita suportou a forte desvalorização do barril, tendo como sustentação principal seu custo de produção muito baixo, sendo em 2015 , inferior a US $\$ 10$ para um barril de petróleo (Rystad Energy, 2015).

Ademais, com a revogação das sanções contra o Irã, devido ao acordo firmado entre as potências mundiais (EUA, Grã-Bretanha, Alemanha, China, França e Rússia) e o programa nuclear iraniano em julho de 2015, houve a retomada das exportações de petróleo iraniano para o ocidente. Com isso, houve uma pressão ainda maior sobre os preços, dificultando também um acordo entre os membros da OPEP, devido às tensões políticas entre Arábia Saudita e Irã (Bloomberg, 2016).

\section{Considerações Finais}

Neste estudo foi construído um breve levantamento bibliográfico da história do petróleo, relatando-se desde o seu surgimento nos tempos bíblicos até a formação e desenvolvimento da indústria petrolífera. A perspectiva histórica foi abordada segundo tópicos que focalizam o pioneirismo da indústria do petróleo, seu processo de internacionalização e desenvolvimento, até os choques petrolíferos e os eventos que se sucederam.

Cabe informar que o artigo procura relatar os principais eventos que se sucederam durante a história do petróleo, por meio da construção de uma correlação cronológica, a fim de possibilitar uma compreensão geral dos fatos.

\section{Referências}

Aragão, A. P. (2005). Estimativa da Contribuição do Setor Petróleo ao Produto Interno Bruto Brasileiro: 1955/2004 (Dissertação de Mestrado). Universidade Federal do Rio de Janeiro, COPPE, Rio de Janeiro, RJ, Brasil. 152p.

Banco Central Brasileiro (BCB). (2000, Setembro). Relatório de Inflação: Setembro 2000. Acesso em novembro 18, 2017. Disponível em: http://www.bcb. gov.br/htms/relinf/port/2000/09/ri200009b2p.pdf

British Petroleum (BP). (2006). Statistical review of world energy. London, UK. Acesso em outubro 2, 2017. Disponível em: http:// www.bp.com

Bloomberg. (2014). Why Oil Prices Went Down So Far So Fast?. Acesso em novembro 20, 2017. Disponível em: https:/www.bloomberg.com/news/ articles/2014-10-29/why-oil-prices-went-down-

\begin{tabular}{c|c|c|c|c|c|}
\hline (C) Terrae Didat. & Campinas, SP & v.15 & $1-8$ & $\mathrm{e} 019004$ & 2019 \\
\hline
\end{tabular}


so-far-sofast $>$.

Bloomberg. (2016). This Time Mideast Tensions Are Bad News for Oil. Acesso em outubro 21, 2017. Disponível em: https:/www.bloomberg.com/news/ articles/2016-01-04/oil-shrugs-as-glut-bluntsshock-fromdeeper-saudi-iran-conflict

Energy Information Administration (EIA). (2010). Short-Term Energy Outlook - Energy Price Volatility and Forecast Uncertainty. Acesso em Outubro 10, 2017. Disponível em: https://www.eia.gov/outlooks/steo/uncertainty/pdf/oct10_uncertainty.pdf

Energy Information Administration (EIA). (2015). Crude oil proved reserves, 2015. Acesso em outubro 13, 2017. Disponível em: http://www.eia.gov/beta/ international/index.cfm?view $=$ reserves

Energy Information Administration (EIA). (2016). Petroleum \& Other Liquids. Acesso em outubro 13, 2017. Disponível em: http://www.eia.gov/petroleum/data.cfm

Energy Information Administration (EIA). (2017). What Drives Crude Oil Prices: Supply OPEC. Acesso em novembro 18, 2017. Disponível em: http:// www.eia.gov/finance/markets/crudeoil/supplyopec.php

Freret, V.A.C. (2017). Demanda e Produção de Petróleo: Comportamento Futuro (Monografia). Seropédica, RJ, Universidade Federal Rural Rio de Janeiro, Instituto de Agronomia, Departamento de Geociências. 93p.

Gomes, M. (2013). Variação histórica dos preços e das reservas de petróleo brasileiras e internacionais no período
1992 - 2011 (Monografia). Universidade Estadual Paulista "Júlio de Mesquita Filho", Instituto de Geociências e Ciências Exatas, Rio Claro, SP, Brasil. $119 \mathrm{p}$.

Martin, J. M. (1992). A Economia Mundial da Energia. São Paulo, SP: UNESP. 125p.

Penrose, E. (1983). "Defending the price of oil". The Energy Journal, 9(1), 1925.

Rystad Energy. (2015). Rystad Energy on CNN Money. Acesso em novembro 21, 2017. Disponível em: https:/www.rystadenergy.com/NewsEvents/ PressReleases/rystad-energy-on-cnn-money

Shah, S. (2007). A História do Petróleo. Porto Alegre, RS: L\&PM. 240p.

Souza, F. R. (2006). Impacto do preço do petróleo na política energética mundial. (Dissertação de Mestrado). Rio de Janeiro, RJ: Universidade Federal do Rio de Janeiro, COPPE. 160p.

Taverne, B. (1999). Petroleum, industry and governments: An introduction to petroleum regulation, economics and government policies ( $2^{\mathrm{a}} \mathrm{ed}$.). Londres, Reino Unido: Klüwer Law Intern. (426p).

Tugendhat, C. \& Hamilton, A. (1975). Oil, the biggest business. Londres, Reino Unido: Eyre -Methuen. (404p).

WTRG. (2011). Oil Price History and Analysis. Acesso em dezembro 11, 2017. Disponível em: http://www. wtrg.com/prices.htm

Yergin, D. (1990). The prize: the epic quest for oil, money and power. Estados Unidos: Simon \& Schuster. 912p. 